\title{
DESENVOLVIMENTO E PRODUÇÃO DA BANANEIRA 'GRANDE NAINE' SOB DIFERENTES DENSIDADES DE PLANTIO EM REGIÃO COM OCORRÊNCIA NATURAL DE SIGATOKA-NEGRA ${ }^{1}$
}

EDSON SHIGUEAKI NOMURA ${ }^{2}$, ERVAL RAFAEL DAMATTO JUNIOR ${ }^{2}$, EDUARDO JUN FUZITANI ${ }^{2}$, SEBASTIÃO DE OLIVEIRA E SILVA ${ }^{3}$, WILSON DA SILVA MORAES ${ }^{2}$

RESUMO - A alta densidade de plantio de algumas cultivares de bananeira é uma prática utilizável para aumentar a produtividade, sobretudo em regiões afetadas pela Sigatoka. Este trabalho objetivou avaliar o desenvolvimento e a produção de bananeiras 'Grande Naine' cultivadas em diferentes densidades de plantio para a convivência com a Sigatoka-Negra no Vale do Ribeira-SP. Para isso, foi instalado pomar de bananeiras produzidas in vitro da 'Grande Naine', em delineamento inteiramente ao acaso, em esquema fatorial $5 \mathrm{x}$ 2, sendo cinco densidades $\left(2.500 ; 2.222 ; 2.000 ; 1.667\right.$ e 1.111 plantas.ha $\left.^{-1}\right)$ e dois ciclos de produção. A severidade da Sigatoka-Negra foi monitorada semanalmente, utilizando o método de Estado da Evolução (EE) e para o seu controle foram definidas pela segunda progressão consecutiva da severidade e/ou aumento superior a 200 pontos de uma semana para a outra. De cada parcela, oito plantas foram avaliadas quanto à altura, diâmetro do pseudocaule, número de folhas ativas no florescimento e na colheita, massa fresca dos frutos comercializáveis, produtividade, número de pencas e frutos no cacho, massa fresca total e por frutos da $2^{\mathrm{a}}$ penca, comprimento e diâmetro de frutos da $2^{\mathrm{a}}$ penca. Os dados foram submetidos à análise de variância pelo teste $\mathrm{F}$, e as médias, quando significativas, foram comparadas pelo teste de Tukey ( $5 \%$ de probabilidade). Diante das condições experimentais, conclui-se que o adensamento não influenciou no desenvolvimento em altura da planta e no diâmetro do pseudocaule de bananeira 'Grande Naine'. O adensamento de plantas proporcionou maiores produtividades de bananeira 'Grande Naine' nas condições do Vale do Ribera-SP. Termos de indexação: Musa spp.; Mycosphaerella fijiensis Morelet; adensamento; controle químico.

\section{DEVELOPMENT AND PRODUCTION OF BANANA PLANT 'GRANDE NAINE' UNDER DIFFERENT PLANTING DENSITIES IN REAGIONS WITH NATURAL OCCURRENCE OF BLACK LEAF STREAK}

\begin{abstract}
The high density planting of some banana cultivars is an usable practical to increase productivity, especially in regions affected by Sigatoka. This study aimed to evaluate the development and production of banana plant 'Grande Naine' grown in different planting densities with black leaf streak presence at Vale do Ribeira, SP. It was installed a banana orchard with seedlings produced in vitro of the Grande Naine cultivar. The experimental design was a completely randomized, in factorial scheme $5 \times 2$, with five densities $\left(2,500 ; 2,222 ; 2,000 ; 1,667\right.$ and 1,111 plants.ha $\left.^{-1}\right)$ and two production cycles. The black leaf streak severity was weekly monitored using the state evolution method (SE) and its control were set when occurred the second consecutive progression of the severity and/or increases of 200 points from a week to the next. For each plot it was evaluated eight plants measuring plant height, pseudostem diameter, number of active leaves at blooming and at harvest, bunch fresh weight, productivity, number of hands, bunch fruits number, total fresh weight and individual fresh weight of the $2^{\text {nd }}$ hand, length and diameter of $2^{\text {nd }}$ hand fruits. Data were submitted to variance analysis by $\mathrm{F}$ test and the significant means were compared by Tukey test ( $5 \%$ probability). Under the experimental conditions, it can be concluded that the density did not influence the plant development (plant height and pseudostem diameter). The biggest plants density gave higher banana plant 'Grande Naine' yields.
\end{abstract}

Index terms: Musa spp.; Mycosphaerella fijiensis Morelet; density, chemical control.

\footnotetext{
1(Trabalho 053-13). Recebido em: 17-01-2013. Aceito para publicação em: 07-06-2013. Apoio: CNPq - Conselho Nacional de Pesquisa. Proc. 68.0009/2005-1.

${ }^{2}$ Pesquisadores científicos da Agência Paulista de Tecnologia dos Agronegócios - APTA Regional Vale do Ribeira. E-mail: edsonnomura@apta.sp.gov.br, erval@apta.sp.gov.br, edufuzitani@apta.sp.gov.br,wilson@apta.sp.gov.br

${ }^{3}$ Pesquisador da Empresa Brasileira de Pesquisa Agropecuária - Mandioca e Fruticultura. e-mail: ssilva@cnpmf.embrapa.br
} 


\section{INTRODUÇÃO}

Para reduzir o custo de produção da bananeira, têm-se recomendando modificações no sistema de manejo, sendo que alta densidade de plantio de algumas cultivares de bananeiras é uma prática utilizável para aumentar a produtividade. A maioria dos estudos de densidade de plantio tem como objetivo principal avaliar sua influência no crescimento e na produtividade das bananeiras (LANGDON et al., 2008). Além do aumento da produtividade, Orozco-Santos et al. (2008) também relataram vantagens do adensamento para a redução da incidência e severidade do ataque das Sigatokas (Amarela e Negra), como resultado de modificação de algumas condições ambientais dentro da plantação, principalmente da umidade relativa e da temperatura.

Em todas as regiões do mundo onde ocorre, a Sigatoka-Negra (ocasionada pelo fungo Mycosphaerella fijiensis Morelet) constitui-se no principal fator de queda na produtividade dos bananais, com redução de até $100 \%$ na produção (SOTO, 2011), a partir do primeiro ciclo de cultivo. O combate da Sigatoka-Negra em bananeiras depende principalmente da aplicação contínua de fungicidas e, consequentemente, aumento no custo de produção (OROZCO-SANTOS et al., 2008).

Diante do exposto, este trabalho objetivou avaliar o desenvolvimento e a produção de bananeiras 'Grande Naine' submetidas a diferentes densidades de plantio para a convivência com a Sigatoka-Negra na região do Vale do Ribeira-SP.

\section{MATERIAL E MÉTODOS}

O experimento foi conduzido na Agência Paulista de Tecnologia dos Agronegócios - APTA, Regional Vale do Ribeira, Pariquera-Açu-SP (2436'31" S; 4753'48" O), no período de 2010 a 2012, onde o clima da região é classificado como tropical chuvoso, sem estação seca (Af), segundo a classificação de Köppen. Dados de uma série de 10 anos (2001-2011) mostram que as médias anuais da temperatura máxima e mínina foram de $26,7^{\circ} \mathrm{C}$ e 17,1 ${ }^{\circ} \mathrm{C}$, respectivamente, e a pluviosidade média foi de 1.715,6 mm anuais (CIIAGRO, 2012).

O delineamento experimental adotado foi o inteiramente casualizado, em esquema fatorial 5 $\mathrm{x} 2$, sendo os tratamentos constituídos por cinco densidades de plantio: $2.500(2,0 \mathrm{~m} \mathrm{x} \mathrm{2,0} \mathrm{m),} 2.222$ (4,0 m x 2,0 m x 1,5 m), $2.000(2,5 \mathrm{~m} \mathrm{x} \mathrm{2,0} \mathrm{m),} 1.667$ $(3,0 \mathrm{~m} \times 2,0 \mathrm{~m})$ e 1.111 plantas.ha $^{-1}(3,0 \mathrm{~m} \times 3,0 \mathrm{~m})$, avaliadas em dois ciclos consecutivos. Para cada tratamento, foram selecionadas aleatoriamente oito plantas para a coleta de dados do desenvolvimento e da produção das bananeiras. A área experimental foi instalada em local de ocorrência natural da SigatokaNegra, utilizando-se de mudas de bananeiras micropropagadas em laboratório de 'Grande Naine'.

A severidade da Sigatoka-Negra foi monitorada semanalmente em dez plantas por parcela, utilizando o método de Estado da Evolução (EE), adaptado por Fouré (1988). As aplicações de fungicidas foram definidas pela segunda progressão consecutiva da severidade e/ou aumento superior a 200 pontos de uma semana para a outra. Realizaram-se os tratamentos químicos com aplicações alternadas de fungicidas sistêmicos dos grupos químicos triazol e estrobirulina, no período chuvoso e temperaturas elevadas, e com fungicidas do grupo químico benzimidazol no período menos chuvoso e temperaturas amenas. Aliado ao tratamento químico, realizouse a desfolha fitossanitária, que correspondeu na eliminação de folhas inteiras ou parte da folha que apresentava os estádios finais de desenvolvimento da Sigatoka-Negra. Os gráficos de estádios de evolução da Sigatoka-Negra e as aplicações de fungicidas são apresentados na Figura 1 e Tabela 1, respectivamente.

Os cálculos das quantidades de fertilizante de plantio e formação foram realizados de acordo com os resultados da análise de solo, sendo $270 \mathrm{~kg} \cdot \mathrm{ha}^{-1}$ de $\mathrm{N}, 110 \mathrm{~kg} \cdot \mathrm{ha}^{-1}$ de $\mathrm{P}_{2} \mathrm{O}_{5}$ e $490 \mathrm{~kg} \cdot \mathrm{ha}^{-1}$ de $\mathrm{K}_{2} \mathrm{O}$, conforme recomendações de Teixeira et al. (1997), aplicados de forma homogênea em todas as parcelas experimentais. $\mathrm{O}$ controle de plantas daninhas foi realizado por meio da aplicação de herbicida à base de glufosinato de amônia $\left(0,5 \mathrm{~L} \cdot \mathrm{ha}^{-1}\right)$. O desbaste foi realizado quando as folhas dos perfilhos deixaram de ser lanceoladas.

Avaliaram-se em dois ciclos de produção os seguintes parâmetros de desenvolvimento das bananeiras: altura da planta (do nível do solo até a roseta foliar), perímetro (P) do pseudocaule a $30 \mathrm{~cm}$ acima do nível do solo, onde se calcularam o diâmetro $(\mathrm{D}=$ $\mathrm{P} / \pi$ ) e o número de folhas ativas (com mais da metade do limbo verde) no florescimento e na colheita; e parâmetros de produção das bananeiras: massa fresca dos frutos comercializáveis, produtividade (calculado a partir da massa fresca dos frutos comercializáveis e densidade de plantio), número de pencas por cacho, número total de frutos, massa fresca da $2^{\mathrm{a}}$ penca, massa fresca por fruto da $2^{\mathrm{a}}$ penca (calculada a partir da divisão da massa fresca da $2^{\mathrm{a}}$ penca pelo número de frutos $2^{\mathrm{a}}$ penca), comprimento e diâmetro de frutos da $2^{\mathrm{a}}$ penca. Os dados foram submetidos à análise de variância pelo teste $\mathrm{F}$ e, quando significativas, as médias foram comparadas pelo teste de Tukey, a 5 $\%$ de probabilidade. 


\section{RESULTADOS E DISCUSSÃO}

A altura das plantas não foi influenciada pelas densidades de plantio nos dois ciclos de produção (Tabela 2), com médias de $188,3 \mathrm{~cm}$ no $1^{\circ}$ ciclo e $236,8 \mathrm{~cm}$ no $2^{\circ}$ ciclo, porém com diferenças entre os ciclos de produção em todas as densidades. Resultados de pesquisas realizadas em diferentes condições edafoclimáticas mostraram variações em altura da bananeira 'Grande Naine' entre 176,0 a $244,5 \mathrm{~cm}$ no $1^{\circ}$ ciclo e 183,0 a $300 \mathrm{~cm}$ no $2^{\circ}$ ciclo (DONATO et al., 2006; OLIVEIRA et al., 2007; OLIVEIRA et al., 2008), corroborando os resultados obtidos nas diferentes densidades e ciclos deste experimento. Lichtemberg et al. (1997) utilizaram os espaçamentos com 1.667, 2.000 e 2.500 planta. $\mathrm{ha}^{-1} \mathrm{e}$ observaram que a altura média das plantas no florescimento foi maior com o aumento da densidade de plantio, efeito relacionado com a competição intraespecífica para à utilização de luz. Porém este fato não foi observado neste trabalho, devido a utilização da densidade máxima de 2.500 plantas $\mathrm{ha}^{-1} \mathrm{e}$ condições edafoclimáticas mais favoráveis ao cultivo de bananeiras.

Para o diâmetro do pseudocaule, não se observou influência da densidade no $1^{\circ}$ ciclo de produção, com média de 17,4 cm (Tabela 2). No $2^{\circ}$ ciclo, observou-se maior diâmetro na densidade de 2.000 plantas.ha ${ }^{-1}(23,1 \mathrm{~cm})$, porém diferindo somente quando comparado com a densidade de 2.222 plantas.ha ${ }^{-1}(21,0 \mathrm{~cm})$. Houve maiores diâmetros do pseudocaule no $2^{\circ}$ ciclo de produção, em todas as densidades de plantio. Na literatura, são encontrados valores do diâmetro de pseudocaule de 'Grande Naine' entre 16,0 a $25,2 \mathrm{~cm}$ no $1^{\circ}$ ciclo e 20,1 a 33,0 $\mathrm{cm}$ no $2^{\circ}$ ciclo (DONATO et al., 2006; OLIVEIRA et al., 2007; OLIVEIRA et al., 2008), semelhante aos resultados obtidos nas diferentes densidades de plantio e ciclos de produção.

O número de folhas no florescimento foi influenciado pela densidade somente no $2^{\circ}$ ciclo, com maior quantidade na densidade de 1.111 plantas.ha $^{-1}$ $(13,9)$, porém diferindo somente quando comparado com a densidade de 2.000 plantas.ha ${ }^{-1}(11,5)$. De acordo com Teixeira et al. (2001), os produtores mantêm na prática, no mínimo, número igual de folhas ativas e de pencas até a colheita, em que, no presente trabalho, foi alcançada em todas as densidades de plantio. No trabalho realizado por Oliveira et al. (2007) em Visconde do Rio Branco (MG), foram obtidos resultados bem próximos aos deste trabalho, apresentando 11,5 folhas no $1^{\circ}$ ciclo e 10,6 folhas ativas no florescimento do $2^{\circ}$ ciclo, porém com a vantagem de o trabalho de Oliveira et al. (2007) ter sido realizado somente sob influência do ataque do fungo da Sigatoka-Amarela (Mycosphaerella musicola Colla).

Quanto ao número de folhas na colheita, foi observado influência das densidades nos dois ciclos produtivos, superioridade alcançada na densidade de 2.500 plantas.ha $^{-1}$ no $1^{\circ}$ ciclo $(7,0)$ e na densidade de 1.111 plantas.ha ${ }^{-1}$ no $2^{\circ}$ ciclo $(5,4)$, porém este diferindo somente quando comparado com a densidade de 2.222 plantas.ha $^{-1}(3,0)$. Em trabalho realizado em Visconde do Rio Branco (MG), no qual se conviviam somente com a Sigatoka- Amarela, a quantidade de folhas na colheita obtidas foi de 2,8 folhas no $1^{\circ}$ ciclo e 4,3 folhas ativas no $2^{\circ}$ ciclo (OLIVEIRA et al., 2007), resultados inferiores ao alcançado neste experimento, demonstrando que as aplicações alternadas de diferentes grupos químicos de fungicidas e baseadas no monitoramento da severidade da Sigatoka-Negra foi eficiente para o controle da doença.

Diante dos dados apresentados na Tabela 3, é possível verificar que a maior massa fresca dos frutos comercializáveis da bananeira 'Grande Naine' foi obtida com a menor densidade de plantas, ou seja, 1.111 plantas.ha ${ }^{-1}$, sendo que, no $1^{\circ}$ ciclo, para essa densidade, a massa média foi de $14,5 \mathrm{~kg}$, estatisticamente semelhante às densidades de 1.667 e 2.222 plantas.ha ${ }^{-1}(12,2$ e 12,6 kg, respectivamente). Isso indica que, quando o número de plantas cultivadas por hectare é menor, estas têm a possibilidade de melhor aproveitar a luminosidade, bem como sofre menor competição por água e nutrientes, o que favorece o desenvolvimento da planta e, consequentemente, a produção de frutos. Os valores médios da massa fresca dos frutos comercializáveis da bananeira 'Grande Naine', no $2^{\circ}$ ciclo de produção, foram estatisticamente superiores ao $1^{\circ}$ ciclo, em todas as densidades, sendo que a maior massa também foi obtida na densidade de 1.111 plantas.ha $^{-1}(22,6 \mathrm{~kg})$, porém não diferindo quando comparados com as densidades de 2.500 e 1.667 plantas.ha $^{-1}$.

Os resultados de massa fresca dos frutos comercializáveis, obtidos no presente trabalho, corroboram os obtidos por Scarpare Filho e Kluge (2001), que observaram que a massa do cacho, na densidade de 3.333 plantas.ha $^{-1}$, foi $15 \%$ a $20 \%$ inferior à observada nas densidades de 1.666 e 1.333 plantas.ha ${ }^{-1}$, na bananeira 'Nanicão' cultivada em Piracicaba-SP.

No entanto, ao calcular a produtividade, observou-se que, apesar da redução da massa fresca dos frutos comercializáveis (Tabela 3), a média das produtividades foi superior nos plantios adensados (2.500 plantas.ha ${ }^{-1}: 27,8$ t.ha ${ }^{-1} ; 2.222$ plantas.ha $^{-1}$ : 
28,1 t.ha- $\left.{ }^{-1}\right)$ no $1^{\circ}$ ciclo de produção, e no $2^{\circ}$ ciclo na densidade de 2.500 plantas.ha ${ }^{-1}\left(46,4\right.$ t.ha $\left.^{-1}\right)$. Com a redução da densidade, o ganho em massa fresca não foi suficiente para elevar a produtividade, ocasionando diferenças entre o mais adensado (2.500 plantas.ha- $\left.{ }^{-1}\right)$ e o menos adensado (1.111 plantas.ha ${ }^{-1}$ ), semelhante aos resultados obtidos por Scarpare Filho e Kluge (2001). Porém estes autores observaram que, estimando a produtividade em t.ha ${ }^{-1} \cdot$ ano $^{-1}$, os valores

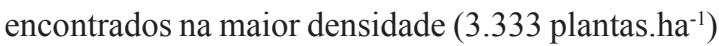
superaram os observados nas outras densidades até o $3^{\circ}$ ciclo, e igualaram-se estatisticamente aos valores encontrados nas demais densidades do $4^{\circ}$ ciclo, devido ao maior ciclo de produção no plantio mais adensado, consequência da competição interplantas.

No $1^{\circ}$ ciclo de produção, o número de pencas foi influenciado pelas diferentes densidades de plantio, verificando-se que a menor média para esse parâmetro foi na densidade de 2.500 plantas.ha $^{-1}$ (Tabela 3 ), porém diferindo somente quando comparado com a densidade 2.222 plantas.ha- ${ }^{-1}$, enquanto no $2^{\circ}$ ciclo esse parâmetro não mostrou resposta às densidades, obtendo, em média, oito pencas por cacho. Em relação aos ciclos de produção, observa-se aumento no número de pencas nas densidades de 2.500, $2.000 \mathrm{e}$ 1.667 plantas.ha ${ }^{-1}$ no $2^{\circ}$ ciclo.

Para o número total de frutos, também somente se observou influência da densidade no $1^{\circ}$ ciclo, com maior quantidade de frutos na densidade de 2.222 plantas.ha ${ }^{-1}$, porém diferindo somente quando comparado com a densidade de 2.500 plantas.ha ${ }^{-1}$. Constatou-se aumento significativo do número total de frutos em todas as densidades do $1^{\circ}$ para o $2^{\circ}$ ciclo de produção.

Quanto à qualidade dos frutos, observa-se no $1^{\circ}$ ciclo que não houve influência das densidades na massa fresca da $2^{\mathrm{a}}$ penca, com média de $2 \mathrm{~kg}$ (Tabela 4), enquanto no $2^{\circ}$ ciclo de produção, a massa fresca da $2^{\mathrm{a}}$ penca foi influenciada pelos tratamentos, sendo que, na densidade de 1.667 plantas.ha ${ }^{-1}$, foi observada maior massa $(3,3 \mathrm{~kg})$, estatisticamente igual à massa obtida na densidade de 1.111 plantas. ha $^{-1}$ (Tabela 4). Comparando os ciclos, observam-se maiores massas da $2^{\mathrm{a}}$ penca no $2^{\circ}$ ciclo produtivo, em todas as densidades.

Em contrapartida, observa-se que houve influência das densidades ao avaliar a massa fresca por frutos da $2^{\text {a }}$ penca, sendo que, na densidade de 1.111 plantas.ha ${ }^{-1}$, apresentou maiores massas nos dois ciclos de produção ( $1^{\circ}$ ciclo: $139,4 \mathrm{~g} ; 2^{\circ}$ ciclo:
181,4 g); porém, no $1^{\circ}$ ciclo, houve diferença somente quando comparado com a densidade de 2.222 plantas.ha $^{-1}(121,3 \mathrm{~g})$. No $2^{\circ}$ ciclo, as massas frescas por frutos da $2^{\mathrm{a}}$ penca foram estatisticamente superiores quando comparados aos do $1^{\circ}$ ciclo produtivo.

$\mathrm{O}$ comprimento de frutos da $2^{\mathrm{a}}$ penca não foi influenciado pelos tratamentos, apresentando médias de 19,2 e $21,9 \mathrm{~cm}$ no $1^{\circ}$ e $2^{\circ}$ ciclos, respectivamente, porém diferiu quando comparado entre os ciclos de produção, enquanto os frutos de maior calibre foram produzidos na densidade de 2.000 plantas.ha $^{-1}$ no $1^{\circ}$ ciclo $(32,7 \mathrm{~mm})$, diferindo somente quando comparados com a densidade de 2.222 plantas.ha $^{-1}$; e de 1.111 plantas.ha- ${ }^{-1}$ no $2^{\circ}$ ciclo $(35,9 \mathrm{~mm})$, diferindo somente quando comparados com a densidade de 2.500 plantas.ha ${ }^{-1}$. De acordo com as normas de classificação do Programa Brasileiro para a Modernização da Horticultura e Produção Integrada de Frutas, nestes tratamentos, os frutos foram classificados na "classe 18 " (frutos de 18 a $22 \mathrm{~cm}$ de comprimento) e na categoria "I" (calibre mínimo de $30 \mathrm{~mm})(\mathrm{PBMH}$ e PIF, 2006). 
TABELA 1- Aplicações alternadas de fungicidas nas diferentes densidades de plantio, Pariquera-Açu-SP, 2012.

\begin{tabular}{|c|c|c|c|c|c|}
\hline \multirow{2}{*}{ Princípios ativos } & \multicolumn{5}{|c|}{ Densidades (plantas.ha-1) } \\
\hline & 2.500 & 2.000 & 1.667 & 2.222 & 1.111 \\
\hline $\begin{array}{l}\text { Trifloxistrobina }\left(100 \text { g. } \mathrm{L}^{-1}\right)+ \\
\text { Tebuconazol }\left(200 \text { g. } \mathrm{L}^{-1}\right)\end{array}$ & $10 / 2010 *$ & $10 / 2010$ & $10 / 2010$ & $10 / 2010$ & $10 / 2010$ \\
\hline \multirow{4}{*}{ Propiconazol (250 g.L.-1) } & $16 / 2010$ & $16 / 2010$ & $16 / 2010$ & $16 / 2010$ & $16 / 2010$ \\
\hline & $48 / 2010$ & $39 / 2010$ & $39 / 2010$ & $39 / 2010$ & $39 / 2010$ \\
\hline & $05 / 2011$ & $03 / 2011$ & $03 / 2011$ & $03 / 2011$ & 03/2011 \\
\hline & $41 / 2011$ & & & & $40 / 2011$ \\
\hline \multirow{4}{*}{ Difenoconazol (250 g.L $\left.L^{-1}\right)$} & $22 / 2010$ & $22 / 2010$ & $22 / 2010$ & $27 / 2010$ & $27 / 2010$ \\
\hline & $15 / 2011$ & $15 / 2011$ & $48 / 2010$ & $10 / 2011$ & $10 / 2011$ \\
\hline & & $41 / 2011$ & $10 / 2011$ & $41 / 2011$ & \\
\hline & & & $41 / 2011$ & & \\
\hline \multirow{2}{*}{ Tiofanato metílico (200 g.L $\left.\mathrm{L}^{-1}\right)$} & $30 / 2010$ & $33 / 2010$ & $34 / 2010$ & \multirow{2}{*}{$34 / 201027 / 2011$} & $34 / 2010$ \\
\hline & $27 / 2011$ & $28 / 2011$ & $27 / 2011$ & & $27 / 2011$ \\
\hline \multirow{4}{*}{ Tebuconazol (200 g.L.-1) } & $39 / 2010$ & $09 / 2011$ & $36 / 2010$ & \multirow{4}{*}{$\begin{array}{c}39 / 2010 \\
07 / 201134 / 2011\end{array}$} & $09 / 2011$ \\
\hline & 09/2011 & $34 / 2011$ & $07 / 2011$ & & $31 / 2011$ \\
\hline & $31 / 2011$ & & 09/2011 & & \\
\hline & & & $34 / 2011$ & & \\
\hline \multirow{2}{*}{ Azoxitrobina (250 g.L $\left.\mathrm{L}^{-1}\right)$} & $53 / 2010$ & $52 / 2010$ & $44 / 2010$ & $52 / 2010$ & $52 / 2010$ \\
\hline & $23 / 2011$ & $23 / 2011$ & $20 / 2011$ & $23 / 2011$ & $19 / 2011$ \\
\hline
\end{tabular}

*semana/ano
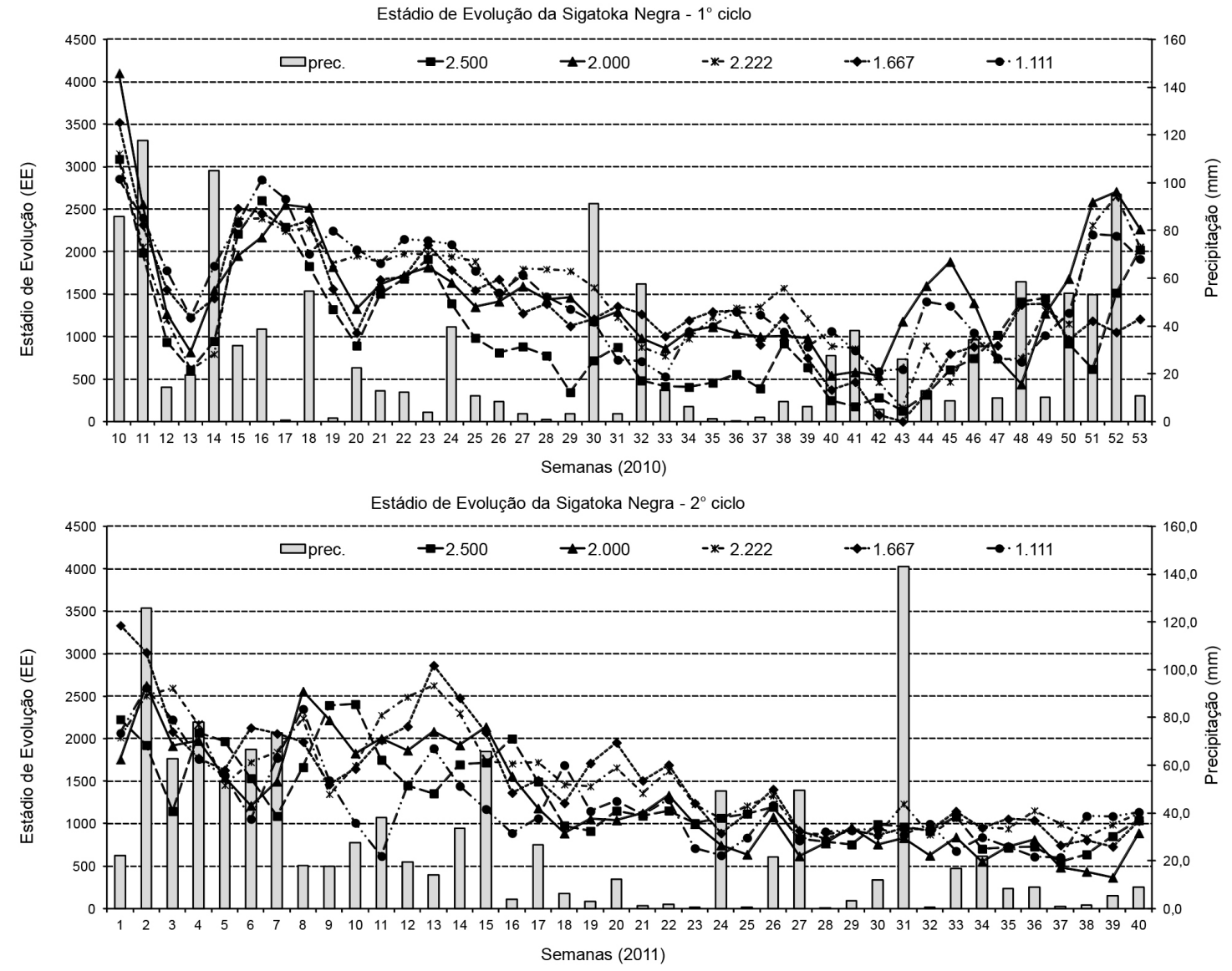

FIGURA 1- Gráfico do Estádio de Evolução da severidade da Sigatoka-Negra e acúmulo de chuvas por semana, Pariquera-Açu-SP, 2012. 


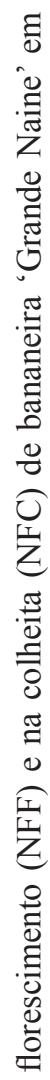

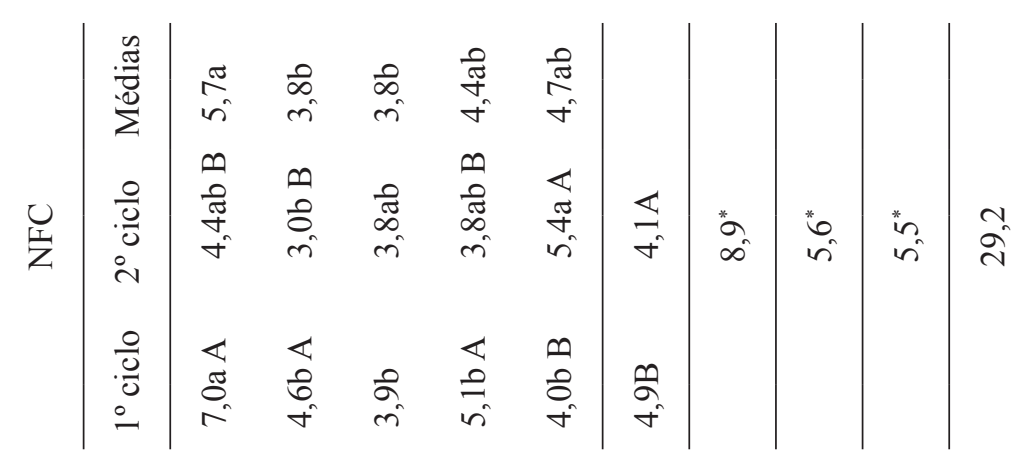

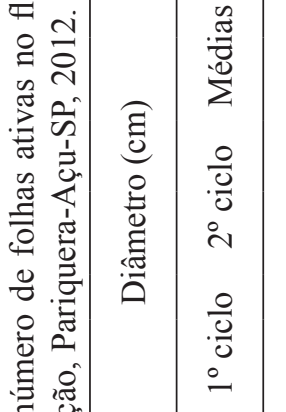

อ :

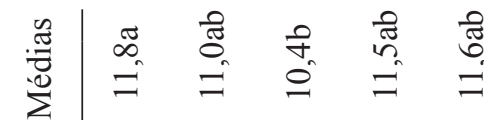

壵

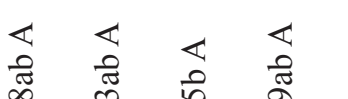

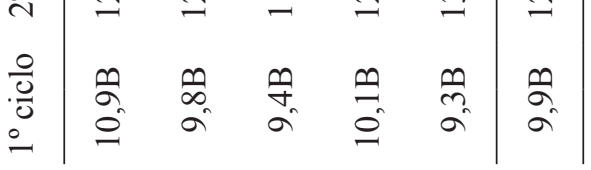

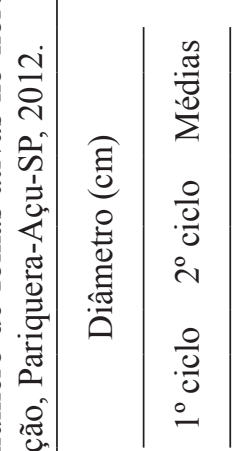

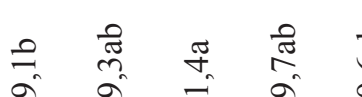

व $\vec{\sim} \stackrel{2}{2}$

$\ll \ll \ll \ll$

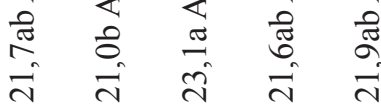

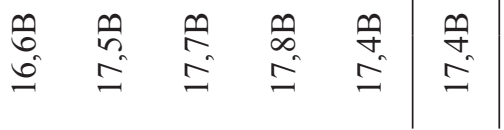

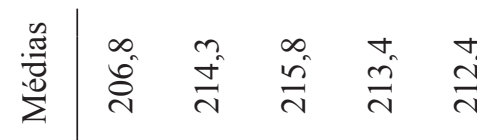

党

है.

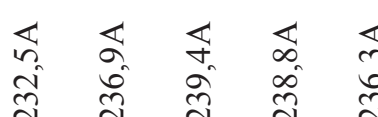

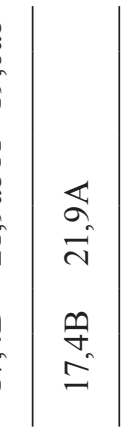

\&

$\frac{0}{0}$ है

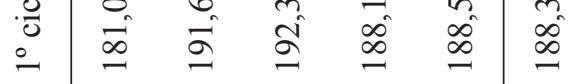

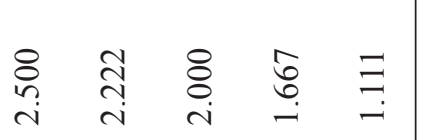

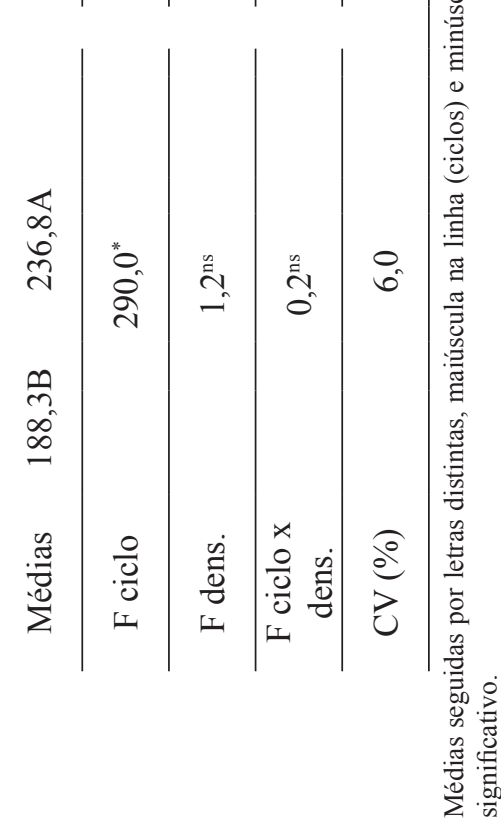




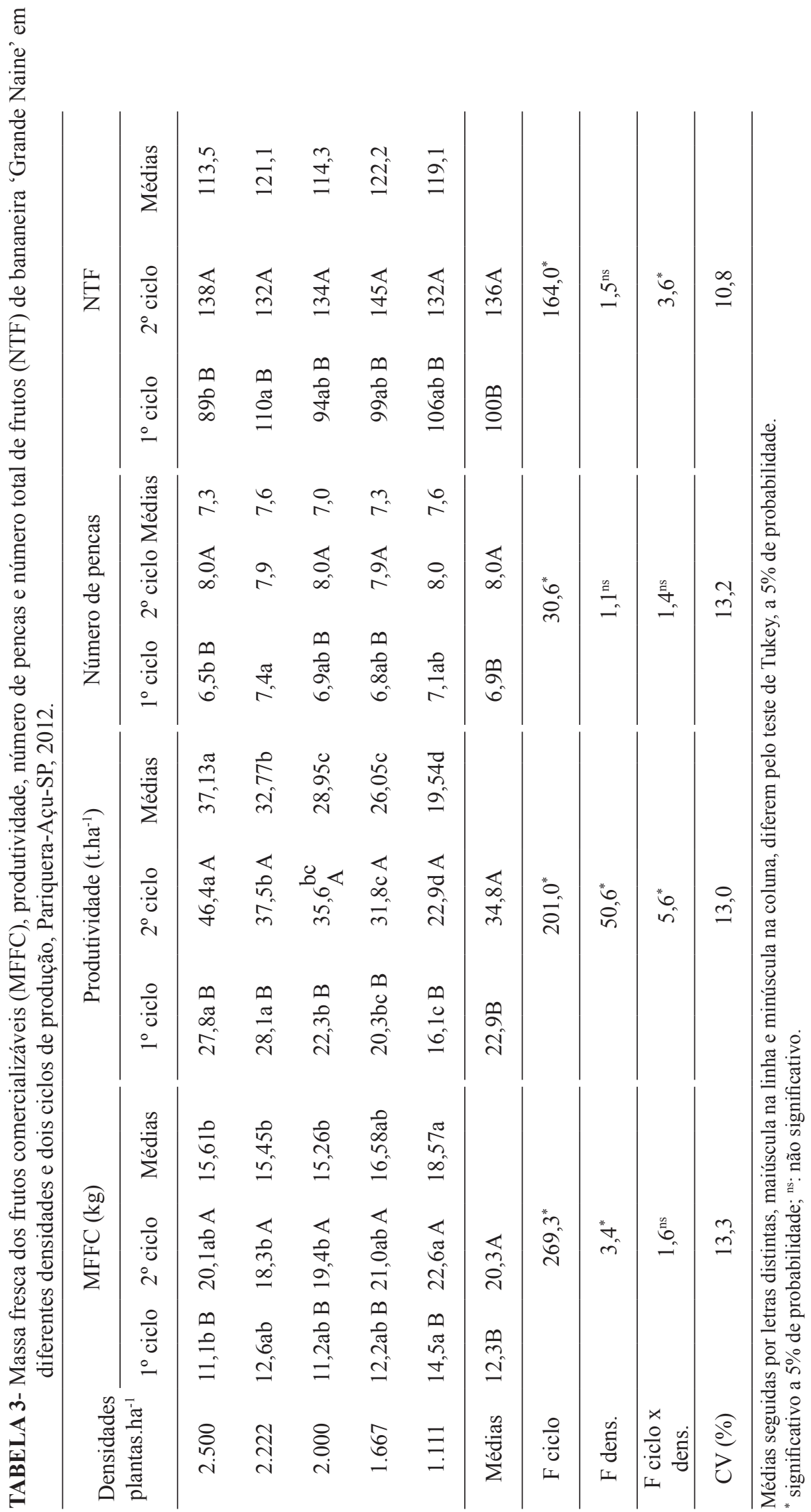




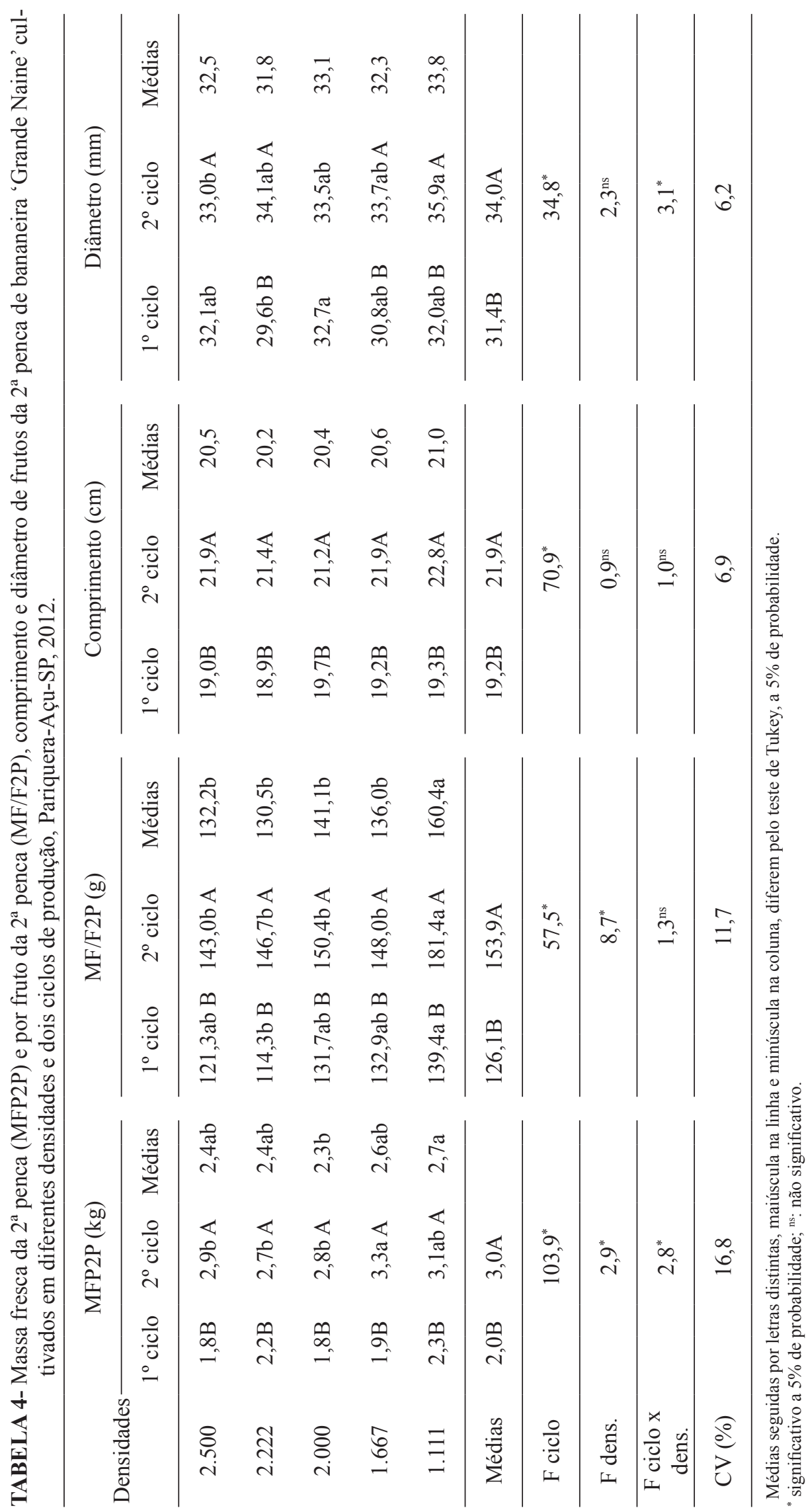




\section{CONCLUSÕES}

Diante das condições experimentais, conclui-se que o adensamento não influenciou no desenvolvimento em altura da planta e no diâmetro do pseudocaule de bananeira 'Grande Naine'. O adensamento de plantas proporcionou maiores produtividades e frutos de melhor qualidade em bananeira 'Grande Naine'.

\section{REFERÊNCIAS}

CIIAGRO - Centro Integrado de Informações Agrometeorológicas. Disponível em: $<\underline{\mathrm{http}} / / / \mathrm{www}$. ciiagro.sp.gov.br >. Acesso em : 20 abr. 2012.

DONATO, S.L.R; SILVA, S.O.; LUCCA FILHO, O.A.; LIMA, M.B.; DOMINGUES, H.; ALVES, J.S. Comportamento de variedades e híbridos de bananeira (Musa spp.), em dois ciclos de produção, no sudoeste da Bahia. Revista Brasileira de Fruticultura, Jaboticabal, v. 28, n.1, p.139-144, 2006.

FOURÉ, E. Stratégies de lutte contre la cercosporiose noire des bananiers et des plantains provoquée par Mycosphaerella fijiensis Morelet. L'avertissement biologique au Cameroun. Evaluation des possibilités d'amélioration. Fruits, Paris, v.43, n.5, p.269-274, 1988.

LANGDOM, P.W.; WHILEY, A.W.; MAYER, R.J.; PEGG, K.G.; SMITH, M.K. The influence of planting density on the production of 'Goldfinger' (Musa spp., AAAB) in the subtropics. Scientia Horticulturae, Amsterdam, v.115, p.238-243, 2008.

LICHTEMBERG, L.A.; HINZ, R.H.; MALBURG, J.L.; STUKER, H. Crescimento e duração dos cinco primeiros ciclos da bananeira 'Nanicão' sob três densidades de plantio. Revista Brasileira de Fruticultura, Jaboticabal, v.19, n.1, p.15-23, 1997.
OLIVEIRA, T.K.; LESSA, L.S.; SILVA, S.O.; OLIVEIRA, J.P. Características agronômicas de genótipos de bananeira em três ciclos de produção, em Rio Branco-AC. Pesquisa Agropecuária Brasileira, Brasília, v. 43, n. 8, p.1003-1010, 2008.

OLIVEIRA, C.A.P.; PEIXOTO, C.P.; SILVA, S.O.; LÉDO, C.A.S.; SALOMÃO, L.C.C. Genótipos de bananeira em três ciclos, na Zona da Mata Mineira. Pesquisa Agropecuária Brasileira, Brasília, v.42, n.2, p.173-181, 2007.

OROZCO-SANTOS, M.; OROZCO-ROMERO, J.; PÉREZ-ZAMORA, O.; MANZO-SÁNCHEZ, J.; FARÍAS-LARIOS, J.; MORAES, W.S. Prácticas culturales para el manejo de la Sigatoka negra en bananos y plátanos. Tropical Plant Pathology, Brasília, v.33, n.3, p.189-196, 2008.

PBMH \& PIF - Programa Brasileiro para a Modernização da Horticultura e Produção Integrada de Frutas. Normas de classificação de banana. São Paulo: CEAGESP, 2006. 4p. (Documento, 29).

SCARPARE FILHO, J.A.; KLUGE, R.A. Produção da bananeira 'Nanicão' em diferentes densidades de plantas e sistemas de espaçamento. Pesquisa Agropecuária Brasileira, Brasília, v.36, n.1, 2001.

SOTO, M. World situation and advances of banana production and technology. Revista Brasileira de Fruticultura, Jaboticabal. v. 33, n. 1 - Edição especial. p. 13-28, 2011.

TEIXEIRA, L.A.J.; RUGGIERO, C.; NATALE, W. Manutenção de folhas ativas em bananeira 'Nanicão' por meio do manejo das adubações nitrogenada e potássica e da irrigação. Revista Brasileira de Fruticultura, Jaboticabal, v. 23, n. 3, p.699-703, 2001.

TEIXEIRA, L.A.J.; SPIRONELLO, A.; QUAGGIO, J.A.; FURLANI, P. Banana. In: RAIJ, B. van; CANTARELLA, H.; QUAGGIO, J.A.; FURLANI, A.M.C. (Ed.). Recomendações de adubação e calagem para o Estado de São Paulo. 2. ed. rev. Campinas: IAC, 1997. p. 131-132. (Boletim Técnico, 100). 